\title{
Exposure Assessment in Nail Salons: An Indoor Air Approach
}

\author{
Cora Roelofs and Tuan Do \\ Department of Work Environment, University of Massachusetts Lowell, Lowell, MA 01854, USA \\ Correspondence should be addressed to Cora Roelofs, cora_roelofs@uml.edu
}

Received 28 November 2011; Accepted 9 January 2012

Academic Editor: C. Murata

Copyright ( 12012 C. Roelofs and T. Do. This is an open access article distributed under the Creative Commons Attribution License, which permits unrestricted use, distribution, and reproduction in any medium, provided the original work is properly cited.

\begin{abstract}
Due to the complexity of the nail salon work environment, traditional approaches to exposure assessment in this context tend to mischaracterize potential hazards as nuisances. For this investigation, a workable "indoor air" approach was devised to characterize potential hazards and ventilation in Boston, Massachusetts area nail salons which are primarily owned and staffed by Vietnamese immigrants. A community-university partnership project recruited salons to participate in a short audit which included carbon dioxide measurements and evaluation of other air quality metrics. Twenty-two salons participated. Seventy-three percent of the salons had spot carbon dioxide measurements in excess of $700 \mathrm{ppm}$, the level corresponding to a ventilation rate recommended for beauty salons. Fourteen salons (64\%) did not have a mechanical ventilation system to provide fresh air and/or exhaust contaminated air. The lack of adequate ventilation is of significant concern because of the presence of potentially hazardous chemicals in salon products and the common self-report of symptoms among nail technicians. Community and worker health may be improved through adoption of recommended ventilation guidelines and reduction in the hazard potential of nail products.
\end{abstract}

\section{Introduction}

Over the past 20 years, nail salons have become a common feature of American towns, malls, and city neighborhoods. The rapid growth of the industry has been fueled by the immigration to the United States of Vietnamese and other Asians who have built an economic niche in affordable manicures, pedicures, and artificial nails [1]. Unfortunately, the strong chemical odors emanating from nail salons have generated complaints to state and local health departments and have stimulated environmental, health, and community advocates to raise concerns about potentially hazardous chemicals used in nail products (see Table 1) [2, 3]. As a result, there is more and more demand for exposure assessment in salons to determine if the smells, vapors, and dusts in nail salons are just a "nuisance" or if they are hazardous to the health of workers and patrons.

The inherent properties of nail product ingredients support the concern about the health of people working often very long work weeks in salons. The toxicity of many ingredients in nail products is clearly established (see Table 1). The Methacrylate Producers Association has published a statement on their website saying that methacylates, including ethyl methacrylate (the principal ingredient in artificial nail preparations) and methacrylic acid (used in nail primers), should not be used in cosmetics due to their toxicity (see http://mpausa.org/aboutmethacrylates/artificial_nails.pdf). Additionally, the potential for human exposure via inhala tion, skin contact, or skin absorption is also apparent. The most popular nail treatments all include a "drying" process where by volatiles are released to the air, leaving a cured surface behind. The California Air Resources Board found that nail hardener and nail polish both emitted formaldehyde at "relatively high emission rates" compared to other consumer products [4].

Few formal industrial hygiene exposure assessment studies have been conducted in nail salons. However, those researchers who have sampled air contaminants have consistently found that nail salon workers are exposed to multiple potentially hazardous chemicals, but at low levels when individual chemicals levels are compared to US Occupational Safety and Health Administration (OSHA) Permissible Exposure Limits and other standards (see Table 2) [5, 6]. The findings of a US National Institute for Occupational Safety and Health (NIOSH) Health Hazard Evaluation of an Ohio nail salon illustrates a "traditional" industrial hygiene 
TABLE 1: Nail products: chemical ingredients and potential health effects.

\begin{tabular}{|c|c|c|c|}
\hline Nail products & Common chemical ingredients & $\begin{array}{l}\text { OSHA PEL/(TLV if lower }) \\
(\mathrm{ppm})\end{array}$ & Potential health effects \\
\hline \multirow{12}{*}{$\begin{array}{l}\text { Nail polish (basecoat, } \\
\text { colors, } \\
\text { and top coats) } \\
\text { Includes: pigments, } \\
\text { resins, solvents, } \\
\text { plasticizers, } \\
\text { dispersants, } \\
\text { and UV stabilizers }\end{array}$} & Ethyl acetate & 400 & Irritation eyes, skin, nose, throat; dermatitis \\
\hline & Butyl acetate & 150 & $\begin{array}{l}\text { Irritation eyes, skin, upper respiratory system; } \\
\text { headache }\end{array}$ \\
\hline & Ethyl alcohol & 1000 & $\begin{array}{l}\text { Irritation eyes, skin, nose; headache, CNS syndrome; } \\
\text { cough; liver damage; anemia; reproductive effects }\end{array}$ \\
\hline & Isopropyl alcohol & 400 & $\begin{array}{l}\text { Irritation eyes, nose, throat; CNS syndrome, } \\
\text { headache; dry, cracking skin }\end{array}$ \\
\hline & Acetone & $1000[250]$ & $\begin{array}{l}\text { Irritation eyes, nose, throat; headache; CNS } \\
\text { syndrome; dermatitis }\end{array}$ \\
\hline & Methyl ethyl ketone & 200 & $\begin{array}{l}\text { Irritation eyes, nose, throat; headache; CNS } \\
\text { syndrome; dermatitis }\end{array}$ \\
\hline & Toluene & $200[50]$ & $\begin{array}{l}\text { Irritation eyes, nose, throat; headache; CNS } \\
\text { syndrome; dermatitis; dilated pupils, lacrimation; } \\
\text { anxiety, muscle fatigue, insomnia; paresthesia; liver, } \\
\text { kidney damage; }\end{array}$ \\
\hline & Xylene & 100 & $\begin{array}{l}\text { Irritation eyes, nose, throat; headache; CNS } \\
\text { syndrome; corneal damage; dermatitis; reproductive } \\
\text { effects }\end{array}$ \\
\hline & Dibutyl phthalate & $5 \mathrm{mg} / \mathrm{m}^{3}$ & $\begin{array}{l}\text { Irritation eyes, upper respiratory system, stomach; } \\
\text { reproductive effects (fetotoxic) }\end{array}$ \\
\hline & Nitrocellulose & None $[400]$ & Unknown \\
\hline & $\begin{array}{l}\text { Toluene Sulfonamide } \\
\text { Formaldehyde Resin }\end{array}$ & None & Dermatitis \\
\hline & Titanium dioxide & $10 \mathrm{mg} / \mathrm{m}^{3}$ & Lung fibrosis; potential occupational carcinogen \\
\hline \multirow{3}{*}{ Nail polish removers } & Acetone & $1000[250]$ & See above \\
\hline & Ethyl acetate & 400 & See above \\
\hline & Butyl Acetate & 150 & See above \\
\hline \multirow{5}{*}{$\begin{array}{l}\text { Artificial nails } \\
\text { Includes: acrylic } \\
\text { polymers, } \\
\text { hardeners, primers, } \\
\text { dehydrators }\end{array}$} & Ethyl methacrylate & None & $\begin{array}{l}\text { Irritation eyes, skin, nose, throat; allergic contact } \\
\text { dermatitis; asthma }\end{array}$ \\
\hline & Methyl methacrylate & $100[50]$ & $\begin{array}{l}\text { Irritation eyes, skin, nose, throat; allergic contact } \\
\text { dermatitis; asthma }\end{array}$ \\
\hline & Butyl methacrylate & None & $\begin{array}{l}\text { Irritation eyes, skin, nose, throat; allergic contact } \\
\text { dermatitis; asthma }\end{array}$ \\
\hline & Methacrylic acid & None $[20]$ & $\begin{array}{l}\text { Irritation eyes, skin, mucous membrane; eye, skin } \\
\text { burns }\end{array}$ \\
\hline & Methyl ethyl ketone & 200 & See above \\
\hline Nail tips adhesives & Ethyl cyanoacrylate & None $[0.2]$ & $\begin{array}{l}\text { Irritation eyes, skin, nose, throat; allergic contact } \\
\text { dermatitis; asthma }\end{array}$ \\
\hline \multirow{3}{*}{$\begin{array}{l}\text { Artificial nail } \\
\text { removers }\end{array}$} & Acetone & $1000[250]$ & see above \\
\hline & N-methyl pyrrolidone & None & Dermatitis, reproductive effects \\
\hline & Acetonitrile & $40[20]$ & $\begin{array}{l}\text { Irritation nose, throat; asphyxia; nausea, vomiting; } \\
\text { chest pain; CNS syndrome; convulsions; in animals: } \\
\text { liver, kidney damage }\end{array}$ \\
\hline Nail hardener & Formaldehyde & & \\
\hline
\end{tabular}

Sources. ACGIH, 2002 TLVs and BEIs; NIOSH Pocket Guide to Chemical Hazards; nail products Material Safety Data Sheets. 
TABLE 2: Summary of air contaminant levels in nails salons.

\begin{tabular}{|c|c|c|c|c|c|c|c|}
\hline & \multicolumn{2}{|c|}{ Occupational exposure limits } & \multicolumn{5}{|c|}{ Mean $8 \mathrm{hr}$ time weighted Avg concentrations } \\
\hline & OSHA PEL & ACGIH TLV & NIOSH I ${ }^{\mathrm{A}}$ & NIOSH II ${ }^{\mathrm{B}}$ & $\begin{array}{l}\text { Froines and } \\
\text { Garabrant }{ }^{\mathrm{C}}\end{array}$ & $\begin{array}{l}\text { Hiipakka and } \\
\text { Samimi }^{\mathrm{D}}\end{array}$ & Maxfield $^{\mathrm{E}}$ \\
\hline \multicolumn{8}{|c|}{ Vapors (ppm) } \\
\hline $\begin{array}{l}\text { MMA } \\
\text { (unvented) } \\
\text { (vented) }\end{array}$ & 100 & 50 & & n.d. $(<3.6)$ & 5.3 & & \\
\hline $\begin{array}{l}\text { EMA } \\
\quad \text { (unvented) } \\
\text { (vented) }\end{array}$ & None & None & $\begin{array}{l}9.4 \\
0.7\end{array}$ & 7.0 & 7.3 & 4.5 & \\
\hline Toluene & 200 & 50 & & & & 0.8 & \\
\hline Isopropyl Alcohol & 1400 & 400 & & & & 15.6 & \\
\hline Butyl Acetate & 150 & & & & & 0.4 & \\
\hline Acetone & 1000 & & & 10.0 & & & \\
\hline \multicolumn{8}{|c|}{ Nuisance dusts $\left(\mathrm{mg} / \mathrm{m}^{3}\right)$} \\
\hline $\begin{array}{l}\text { Unvented, hand } \\
\text { filing }\end{array}$ & & & & & & & 0.15 \\
\hline $\begin{array}{l}\text { Unvented, } \\
\text { Machine filing }\end{array}$ & 15 & 10 & & & & 1.4 & 0.28 \\
\hline $\begin{array}{l}\text { Vented, Machine } \\
\text { filing }\end{array}$ & & & & & & & 0.24 \\
\hline
\end{tabular}

exposure assessment perspective for this context. NIOSH had been requested to investigate this nail salon by a neighboring business complaining of a terrible odor. NIOSH measured ethyl methacrylate (the chemical used to make artificial nails) and acetone and found levels 10 times lower than NIOSH's recommended exposure limits. They also found that the nail salon lacked any mechanical ventilation. Thus, NIOSH concluded:

\begin{abstract}
Several chemicals (methacrylates, acetone) used in nail salons emit vapors that have low odor thresholds. Under certain conditions, these odors can be detectable in adjacent businesses. However, concentrations of these vapors, as measured on the day of the NIOSH survey, do not constitute a health hazard to the workers and customers of at Tina and Angela's Nail salon or to adjacent businesses. http://www.cdc.gov/ niosh/hhe/reports/pdfs/1992-0128-2241.pdf.
\end{abstract}

Despite failing to find hazardous exposures, like other investigators, NIOSH recommended that salons assure adequate ventilation-both general and local exhaust-to provide fresh air and the exhausting of contaminated air.

While salon chemical concentrations are unlikely to exceed established exposure limits, work-related health complaints by nail salon workers are common. One survey of Boston area nail technicians found that self-reported work-related health symptoms such as skin and respiratory irritation, difficulty breathing, headaches, and trouble concentrating were reported by significant percentages of the workers surveyed (see Table 3) [7]. Additionally, the workers reported high levels of concern about chemical exposures at work and almost universal (voluntary) use of masks. Nail technicians frequently reported the use of infection control masks to protect against inhalation of chemical vapors, despite their lack of utility for that purpose.

Though limited in number and scope, other studies have also found health effects in this worker population: Hiipakka and Samimi's symptom survey of 20 nail technicians and controls found greater prevalence of respiratory irritation in nail technicians [5]. LoSasso et al. found neurological deficits in a study of 150 nail technicians versus controls $[8,9]$. John et al. found that manicurists and nail sculptors were at increased risk of spontaneous abortion [10]. Health effects have been well documented in other workers, such as dental technicians, who work with one of the principal chemicals used in nail salons: ethyl methacrylate [11-14].

As in the case of troublesome indoor air quality in office environments, a finding of low exposure levels in nail salons may not equate to a finding of a healthful work environment. Indeed, chemical-by-chemical exposure assessment in nail salons is not likely to answer questions about the relevance of exposures to potential health effects. Exposures are likely to be to a mixture of multiple chemicals, chemicals in vapor and dust forms, and to chemicals without exposure limits or accepted epidemiological findings. Air contaminant sampling and comparison to occupational exposure limits cannot generally address the effects of chemicals most relevant to salon exposures and workers: skin absorption, skin contact, sensitization, reproductive health concerns, headaches, neuropsychological effects, and/or respiratory, dermal, or sensory irritation. Additionally, the diversity of potential salon exposures and exposure factors (e.g., range of products, extended hours of work) would 
TABLE 3: Self-reported work-related* health effects and among Vietnamese-American nail technicians $(n=71)$.

\begin{tabular}{lc}
\hline Health effect & Frequency (\%) \\
\hline Respiratory irritation & $16(23 \%)$ \\
$\begin{array}{l}\text { Difficulty breathing } \\
\text { Any respiratory symptom (difficulty breathing, }\end{array}$ & $8(11 \%)$ \\
regular cough, sinus/nasal, irritation) & $21(30 \%)$ \\
Headaches & $31(44 \%)$ \\
Difficulty concentrating & $20(28 \%)$ \\
Allergic to something at work & $17(25 \%)$ \\
Seen a doctor for work-related health problem & $15(21 \%)$ \\
${ }^{*}$ Note. Work-relatedness was determined by asking respondents about \\
symptoms and, separately, if the symptom improved with time away from \\
work.
\end{tabular}

require an extraordinary number of samples in order to establish reference frameworks that would assure baseline safety. Even such results would expire rapidly as products changed.

Given these contextual factors, an "indoor air" approach to exposure assessment was suggested for evaluation of the nail salon work environment. This study piloted a qualitative assessment strategy that would quickly identify the presence or absence of various relevant exposure determinants: the presence of volatile toxic compounds, disagreeable odors, inadequate ventilation, and health complaints related to nail salon work that might suggest an extreme type of indoor air quality problem and distinguish between "better" and "worse" conditions [18]. Exposures to the types of chemicals in nail products-organic solvents, formaldehyde, and acrylic compounds-and low ventilation rates have both been associated with the symptoms reported in our survey $[19,20]$. Because a previous study had found that nail salon owners and staff were often not able to correctly describe the air handling devices in their salons, ventilation and other exposure metrics were assessed through a salon audit conducted by a trained researcher [7]. In addition to metrics relating to the volume of chemical use and the number of exposed individuals, the audit focused on gaining an understanding of the adequacy of fresh air in salons.

The American Society of Heating, Refrigerating and Air-Conditioning Engineers (ASHRAE) recommends that beauty salons maintain 25 cubic feet per minute $(\mathrm{cfm})(0.71$ cubic meter per minute) of fresh air per person via mechanical ventilation [21]. This guideline would correspond to a measured level of 700 parts per million (ppm) of carbon dioxide in an indoor environment. (Carbon dioxide levels range from 300 to $600 \mathrm{ppm}$ in outside uncontaminated air.) There are no requirements or guidelines for the exhausting of salon air, although the National Institute for Occupational Safety and Health has developed guidance for local exhaust ventilation via downdraft ventilation in nail tables [22].

Our project, like others, faced challenges in conducting research in the nail salon setting [23]. Recruitment of participants was potentially burdened by language and other social and economic barriers. Even when language issues are overcome, salon owners may fear that the presence of researchers will disrupt or discourage business or attract unwanted regulatory attention [24]. Salon staff may fear negative publicity that might impact their ability to earn a living $[25,26]$. In order to overcome these barriers, a collaborative process between a Vietnamese community and economic development organization, the VietnameseAmerican Initiative for Development, Inc. (Viet-AID), and a University, the University of Massachusetts Lowell, was used to develop and carry out the research. Additionally, the approach was designed to limit business disruption, to be able to be used while customers were present in the salon, and with a view toward potential adaptation for use by local health departments.

\section{Materials and Methods}

Short air quality audits were conducted in 22 salons over three months in early summer 2006 in the Greater Boston area. The field researcher (one of the authors) is occupational health graduate student and a native Vietnamese speaker. Though a convenience sample, salons were selected from different geographic areas that represent the distribution of salons throughout the area. Five salons were recruited to participate by one of the authors. Of these five, four had been featured in a marketing, outreach, and education project conducted by the university-community partnership: the "Healthy Nail Salon Work Environment" bilingual calendar. In addition to recruiting from Viet-AID's network, several salons were recruited "on-the-spot." The field researcher approached salons during nonbusy periods and requested participation in the audit. Of the 47 that were approached, 17 agreed to participate. All salon representatives signed Informed Consent Forms in Vietnamese or English approved by the University of Massachusetts Institutional Review Board. Participating salons received a copy of the calendar, a \$20 grocery store certificate, and a full report in English and Vietnamese on the findings of the audit and recommendations for air quality improvement.

The audit recorded basic business information as provided by a salon owner or worker, the researcher's observations of air movement equipment and natural ventilation, and measured temperature, humidity, and carbon dioxide level. Carbon dioxide level was used as a surrogate for the salon's ventilation rate. In an occupied space, carbon dioxide levels can be compared to natural outside levels (300-600 ppm) to evaluate the adequacy of fresh air (people are the principal source of carbon dioxide indoors). Temperature, humidity, and carbon dioxide were measured with a calibrated TSI Q-Trak monitor. The monitor was placed in the work area and allowed to equilibrate without any person within three feet of the monitor. Audit data was transferred to an Excel spreadsheet and basic analysis was conducted within Excel. 
TABLE 4: Ventilation characteristics of 22 Boston area nail salons.

\begin{tabular}{|c|c|c|c|}
\hline \multirow{2}{*}{ Mechanical ventilation } & Yes & 8 & $36 \%$ \\
\hline & No & 14 & $64 \%$ \\
\hline \multirow{2}{*}{ Ventilation working } & Verified & 9 & $41 \%$ \\
\hline & Do not know & 13 & $59 \%$ \\
\hline \multirow{2}{*}{ Local exhaust } & Yes & 1 & $5 \%$ \\
\hline & No & 21 & $95 \%$ \\
\hline \multirow{6}{*}{ Other ventilation (salons using) } & Room a/c & 20 & $91 \%$ \\
\hline & Open doors/windows & 13 & $59 \%$ \\
\hline & Air purifyers & 5 & $23 \%$ \\
\hline & Room fan & 4 & $18 \%$ \\
\hline & Exhaust fan & 5 & $23 \%$ \\
\hline & Table fan & 12 & $55 \%$ \\
\hline \multirow{3}{*}{ Shop volume (cubic feet) } & Average & 5,674 & \\
\hline & Low & 1,639 & \\
\hline & High & 15,561 & \\
\hline
\end{tabular}

TABLE 5: Air quality metrics in Boston area nail salons $(n=22)$.

\begin{tabular}{|c|c|c|}
\hline \multirow{3}{*}{ Temperature (degrees Fahrenheit) } & Average & 78 \\
\hline & Low & 57 \\
\hline & High & 90 \\
\hline \multirow{3}{*}{ Relative humidity \% } & Average & 48 \\
\hline & Low & 24 \\
\hline & High & 73 \\
\hline \multirow{6}{*}{ Carbon dioxide (ppm) } & Average & 893 \\
\hline & GM & 845 \\
\hline & Low & 470 \\
\hline & High & 1550 \\
\hline & $700 \mathrm{ppm}$ or more & 16 \\
\hline & 1000 or more & 6 \\
\hline \multirow{3}{*}{ Number of occupants (including survey staff) } & Average & 7 \\
\hline & Low & 2 \\
\hline & High & 14 \\
\hline
\end{tabular}

\section{Results}

The salons in the sample had been in business on an average of four and a half years and none had operated more than 10 years. Two salons were primarily hair salons and had only one manicure table and one manicurist. Most dedicated nail salons had five or more tables and three or more pedicure stations. Three or four nail technicians usually worked in each salon with one salon having as many as 10 workers. Additional nail technicians are usually called in on a Saturday, the busiest day, when these salons averaged 32 manicures and as many as 100 . Seventeen out of the 22 salons performed artificial or "sculpted" nail services and the average amount of "nail liquid," the intensely odorous ethyl methacrylate monomer, used by these shops in a month was 24 ounces. Almost all of the shops visited were storefronts; two others were in malls and another was in the upper floor of a building.

Of the 22 salons in our survey, eight had some form of mechanical ventilation. Although the field researcher was not able to verify that these systems delivered fresh air or that these systems were appropriately designed and operated, he did verify that these systems were functional. As shown in Table 4, the salons in the sample rely on a variety of strategies to move and condition air, including room air conditioning units (20), room and table fans (16), open doors and windows (13), stand-alone air cleaners units (5), and wall or ceiling mounted exhaust fans (5). One salon had built a "local exhaust" system whereby commercial vacuum cleaners in the basement were connected to a work area by a hose extended through the ceiling to the tables above.

Table 5 shows that early summer salon temperatures averaged $78^{\circ} \mathrm{F}\left(25.6^{\circ} \mathrm{C}\right)$ with a range of 58 to $90^{\circ} \mathrm{F}(14.4-$ $32.2^{\circ} \mathrm{C}$ ). Relative humidity averaged $48 \%$ with a range of $24-$ $73 \%$. Carbon dioxide levels had a mean of 893 ppm with a range of 470 to $1550 \mathrm{ppm}$. The number of occupants ranged from 2 to 14 with an average of seven. Shops were generally small: the average area was $551 \mathrm{ft}^{2}\left(51.2 \mathrm{~m}^{2}\right)$ and they ranged in size from 216 to $1365 \mathrm{ft}^{2}\left(20.1-126.8 \mathrm{~m}^{2}\right)$. 


\section{Discussion}

In $27 \%$ of the salons, spot carbon dioxide readings exceeded $1000 \mathrm{ppm}$, the level determined by NIOSH and EPA to indicate inadequate ventilation of generally uncontaminated occupied spaces [27]. Seventy-three percent of the salons in the sample had measured spot carbon dioxide readings greater than 700 ppm and most likely not meeting ASHRAE's beauty salon guideline of $25 \mathrm{cfm}$ ( 0.71 cubic meter per minute) of fresh air per person. In half of the salons demonstrating this elevated carbon dioxide reading, there were fewer than seven people, the average number of occupants for this sample. In all but one of the salons with mechanical ventilation, carbon dioxide levels exceeded 700 ppm, suggesting that systems were either not designed to introduce fresh air or were not operating at the time of the measurement. (Several owners reported not using their systems in order to save money on their electric bills). In response to our audit report, one owner upgraded her ventilation system to provide fresh air to the salon. The small business coordinator of Viet-AID was able to assist her in gaining a small business loan in order to do so.

Adequate general ventilation in public and work places is important regardless of the potential contaminants in those spaces. While the small number of salons in our sample prevents us from generalizing, it is likely that most nail salons do not have adequate general ventilation, despite the presence of ventilation systems in some, and a combination of other air moving equipment, such as room air conditioners in others. The lack of adequate ventilation is of significant concern because of the presence of potentially hazardous chemicals in salon products and the common selfreport of symptoms among nail technicians.

This is the first study of its kind to evaluate basic business, indoor air quality, and exposure metrics in nail salons. Although this study collected data from a small nonrandom sample of salons and took a limited number of measurements per salon, some basic information was obtained that will serve salon owners, public health advocates, and consumers in their efforts to understand and address the potential hazards in this popular business. In keeping with the public health mandate to reduce hazards at the source, consumer advocates have pressured some manufacturers to reduce the odor, volatility, toxicity, and hazard potential of nail products and some have done so, particularly in response to new European restrictions on toxic cosmetics ingredients (see http://www.safecosmetics.org/) [28]. Chemicals that have the potential for serious effects such as adverse reproductive outcomes, cancer, and sensitization should be targeted for elimination or control to the lowest feasible levels since "no effect" levels will be difficult to determine.

\section{Conclusion}

Chemical-by-chemical industrial hygiene monitoring is not recommended for exposure assessment in nail salons except, perhaps, in the context of epidemiological studies. Nail technicians are unlikely to be "overexposed" as defined by exposure level standards and such an approach will miss the potential overexposures resulted from mixed chemicals, multiple forms of chemicals, absence of adequate general ventilation, and exposures to chemicals that are absorbed through the skin or cause sensitization (such as dermatitis), reproductive effects, or acute or chronic irritation. Instead, what is recommended is an indoor air exposure assessment strategy to evaluate work environment factors that suggest a potential for health problems and point to workable solutions. This walkthrough audit and interview method looks for sources of potential hazards, including the presence of volatile organic solvents, sensitizing or dermally-absorbed chemicals with recognized toxicities; performs a simple evaluation of work space ventilation; catalogs reported symptoms related to time spent in the salon. The results of this nontechnical assessment could form the basis of recommendations to the salon owner, distinguish between "better" and "worse" salons from the perspective of workers and customers, and advise public health advocates on helpful policy and educational approaches including advocacy of reduction in hazard potential of nail products and promotion of adequate ventilation in salons.

\section{Acknowledgments}

The authors would like to thank the participating salons; Hoa Mai Nguyen and Hiep Chu; Anne Bracker; Drs. Lenore Azaroff, Susan Woskie, and Michael Ellenbecker. The National Institute for Occupational Safety and Health funded this research under Grant K01 OH007956-01. The authors have no conflicts of interests or financial interest in any commercial entity related to this paper.

\section{References}

[1] M. N. Federman, D. E. Harrington, and K. J. Krynski, "Vietnamese manicurists: Are immigrants displacing natives or finding new nails to polish?" Industrial and Labor Relations Review, vol. 59, no. 2, pp. 302-318, 2006.

[2] U.S. Environmental Protection Agency, Office of Pollution Prevention and Toxics: Protecting the Health of Nail Salon Workers, 2007, http://www.epa.gov/dfe/pubs/projects/salon/ nailsalonguide.pdf.

[3] Women's Voices for the Earth: Glossed Over: Health Hazards Associated with Toxic Exposures in Nail Salons, 2007, http://www.coalitionforcleanair.org/pdf/reports/health-hazards-associated-with-toxic-exposure-in-nail-salons.pdf.

[4] T. J. Kelly, D. L. Smith, and J. Satola, "Emission rates of formaldehyde from materials and consumer products found in Califomia homes," Environmental Science and Technology, vol. 33, no. 1, pp. 81-88, 1999.

[5] D. Hiipakka and B. Samimi, "Exposure of acrylic fingernail sculptors to organic vapors and methacrylate dusts," American Industrial Hygiene Association Journal, vol. 48, no. 3, pp. 230237, 1987.

[6] A. B. Spencer, C. F. Estill, J. B. McCammon, R. Mickelsen, and O. E. Johnston, "Sentinel event notification system for occupational risks (SENSOR)," in Depth Survey Report: Control of Ethyl Methacrylate Exposures during the Application of Artificial Fingernails at Moore's University of Hair Design, National 
Institute for Occupational Safety and Health, Cincinnati, Ohio, USA, 1994.

[7] C. Roelofs, L. S. Azaroff, C. Holcroft, H. Nguyen, and T. Doan, "Results from a community-based occupational health survey of Vietnamese-American nail salon workers," Journal of Immigrant and Minority Health, vol. 10, no. 4, pp. 353-361, 2008.

[8] G. L. LoSasso, L. J. Rapport, B. N. Axelrod, and R. Douglas Whitman, "Neurocognitive sequelae of exposure to organic solvents and (meth)acrylates among nail-studio technicians," Neuropsychiatry, Neuropsychology and Behavioral Neurology, vol. 15, no. 1, pp. 44-55, 2002.

[9] A. S. Labarge and R. J. McCaffrey, "Multiple chemical sensitivity: a review of the theoretical and research literature," Neuropsychology Review, vol. 10, no. 4, pp. 183-211, 2000.

[10] E. M. John, D. A. Savitz, and C. M. Shy, "Spontaneous abortions among cosmetologists," Epidemiology, vol. 5, no. 2, pp. 147-155, 1994.

[11] K. Alanko, P. Susitaival, R. Jolanki, and L. Kanerva, "Occupational skin diseases among dental nurses," Contact Dermatitis, vol. 50, no. 2, pp. 77-82, 2004.

[12] B. Savonius, H. Keskinen, M. Tuppurainen, and L. Kanerva, "Occupational respiratory disease caused by acrylates," Clinical and Experimental Allergy, vol. 23, no. 5, pp. 416-424, 1993.

[13] P. Piirilä, U. Hodgson, T. Estlander et al., "Occupational respiratory hypersensitivity in dental personnel," International Archives of Occupational and Environmental Health, vol. 75, no. 4, pp. 209-216, 2002.

[14] P. Piirilä, L. Kanerva, H. Keskinen et al., "Occupational respiratory hypersensitivity caused by preparations containing acrylates in dental personnel," Clinical and Experimental Allergy, vol. 28, no. 11, pp. 1404-1411, 1998.

[15] J. Decker and A. Beasley, "HHE Report: Tina and Angela's Nail Salon," Tech. Rep., Springdale, Ohio, USA, 1992.

[16] J. R. Froines and D. H. Garabrant, "Quantitative evalutaion of manicurists exposure to methyl, ethyl and isobutyl methacrylates during production of synthetic fingernails," Applied Industrial Hygiene, vol. 1, pp. 70-74, 1986.

[17] R. Maxfield and H. L. Howe, Silica Exposure in Artificial Nail Application Salons, 1997, http://www.idph.state. il.us/about/epi/pdf/epi97-8.pdf.

[18] J. D. Spengler, J. M. Samet, and J. F. McCarthy, Indoor Air Quality Handbook, McGraw-Hill, New York, NY, USA, 2001.

[19] O. A. Seppänen, "Association of ventilation rates and $\mathrm{CO}_{2}$ concentrations with health and other responses in commercial and institutional buildings," Indoor Air, vol. 9, no. 4, pp. 226 252, 1999.

[20] C. A. Erdmann and M. G. Apte, "Mucous membrane and lower respiratory building related symptoms in relation to indoor carbon dioxide concentrations in the 100-building BASE dataset," Indoor Air, Supplement, vol. 14, supplement 8, pp. 127-134, 2004.

[21] American Society of Heating, Refrigerating and AirConditioning Engineers: Ventilation for Acceptable Indoor Air Quality ASHRAE Standard 62-2004, ASHRAE, Atlanta, Ga, USA, 2004.

[22] A. B. Spencer, C. Fairfield Estill, J. B. McCammon, and O. E. Johnston, "NIOSH Studies EMA," Nails, pp. 50-54, 1997.

[23] R. Kwapniewski, S. Kozaczka, R. Hauser, M. J. Silva, A. M. Calafat, and S. M. Duty, "Occupational exposure to dibutyl phthalate among manicurists," Journal of Occupational and Environmental Medicine, vol. 50, no. 6, pp. 705-711, 2008.
[24] E. Mounier-Geyssant, V. Oury, L. Mouchot, C. Paris, and D. Zmirou-Navier, "Exposure of hairdressing apprentices to airborne hazardous substances," Environmental Health, vol. 5, article 23, 2006.

[25] M. Chang, "Nonprofit reaches out to salon employees," Inside Bay Area, 2007, http://www.insidebayarea.com/oaklandtribune/ci_5060479? source=email.

[26] S. Greenhouse, "At nail salons, beauty treatments can have a distinctly unglamorous side," The New York Times, 2007.

[27] U.S. Environmental Protection Agency. Indoor Air Division, National Institute for Occupational Safety and Health, "Building air quality : a guide for building owners and facility managers," 1991.

[28] A. Goldman, "OPI removes carcinogen from nail care products," Los Angeles Times, 2007. 


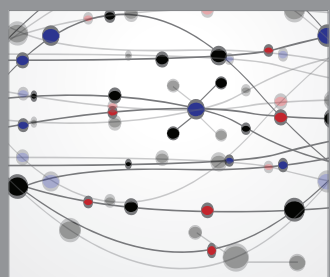

The Scientific World Journal
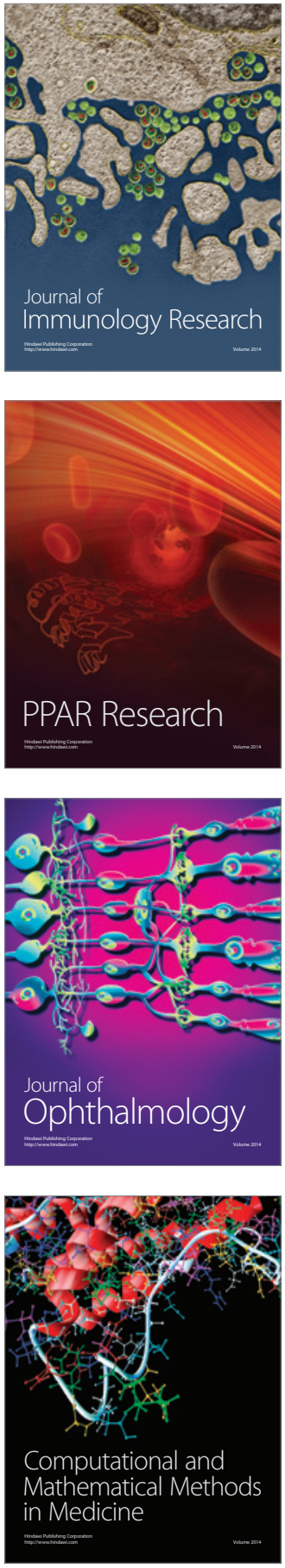

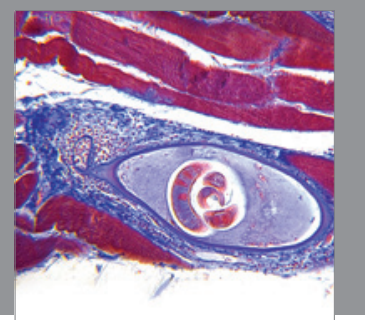

Gastroenterology

Research and Practice
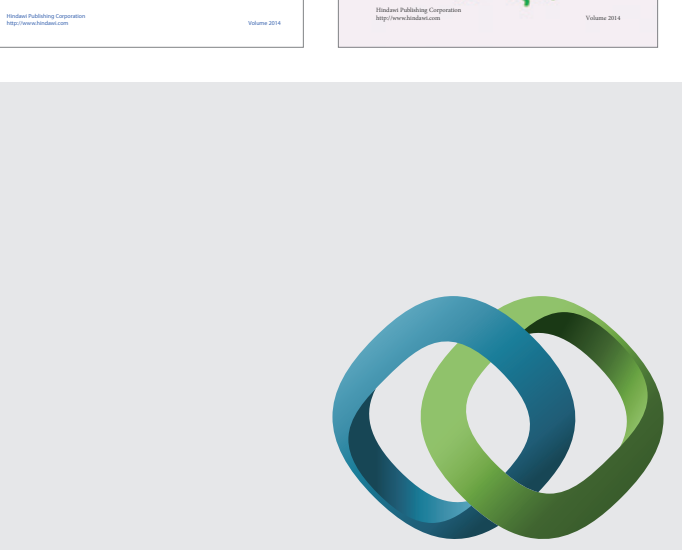

\section{Hindawi}

Submit your manuscripts at

http://www.hindawi.com
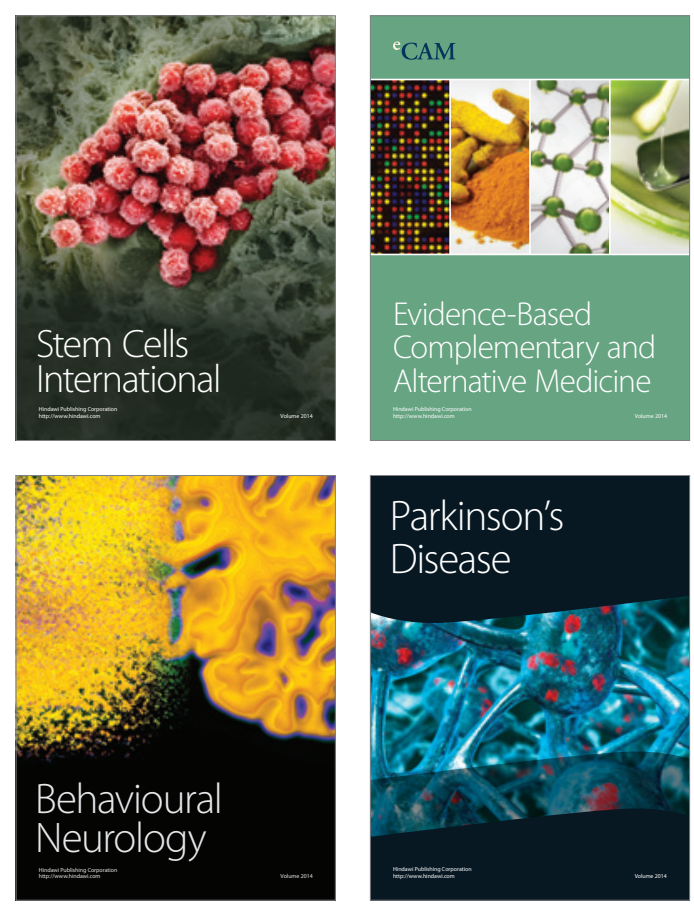

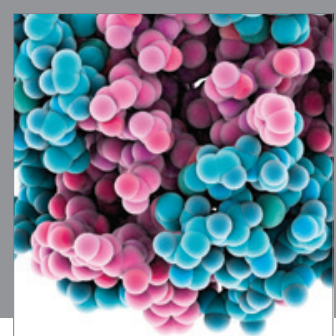

Journal of
Diabetes Research

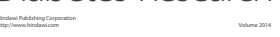

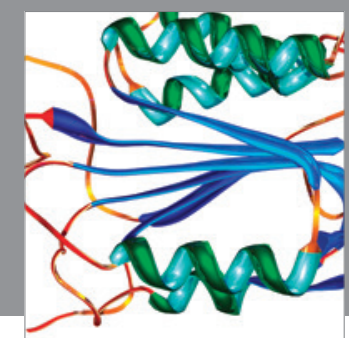

Disease Markers
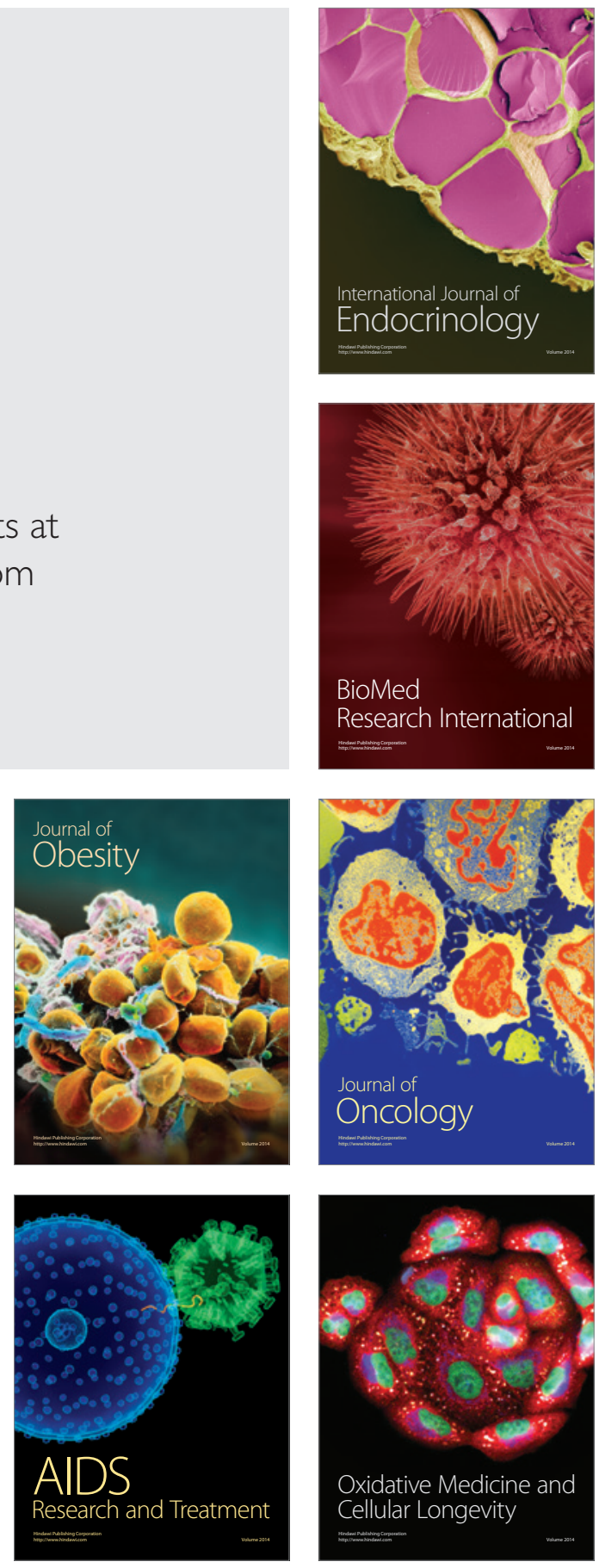